\title{
Is fear of COVID-19 influencing cancer patients to report for follow-up? experience from a tertiary care oncology center in eastern India
}

\author{
Chandrima Ray, Priyanka Singh*, Ranajit Mandal
}

Department of Gynaecological Oncology, Chittaranjan National Cancer Institute, Kolkata, West Bengal, India

Received: 13 October 2020

Revised: 20 October 2020

Accepted: 21 October 2020

\author{
*Correspondence: \\ Dr. Priyanka Singh, \\ E-mail: drpriyankaci@gmail.com
}

Copyright: (C) the author(s), publisher and licensee Medip Academy. This is an open-access article distributed under the terms of the Creative Commons Attribution Non-Commercial License, which permits unrestricted non-commercial use, distribution, and reproduction in any medium, provided the original work is properly cited.

\begin{abstract}
Background: The Coronavirus disease 2019 (COVID-19) pandemic led to the implementation of lockdown in India in March, 2020 which has posed a great challenge for both oncologic health care providers and cancer survivors alike as cancer patients have been unable to report for follow-up visits due to the same. The present study aims to assess the psychological impact of COVID -19 on female cancer patients undergoing treatment in a tertiary care oncology centre in Eastern India.

Methods: The present study is a prospective cross-sectional study conducted on 80 female patients who were undergoing treatment for various gynecologic malignancies at a tertiary care oncology cancer centre in Eastern India. Fear of COVID-19 scale (FCV-19S) was used to assess the psychological impact of COVID-19 among the study population. Telephonic interviews were also conducted to collect data. Data was analysed using Microsoft excel and Statistical package for social sciences (SPSS) version 20.

Results: Seventy-eight percent of the patients were afraid of contracting COVID-19 on coming out of their house, higher number of poorly educated patients had fear of the COVID-19 infection. Fifty-one percent patients were 'very fearful' of the COVID-19 infection and the most common cause of fear was of 'losing life due to corona virus'. Eightysix percent of the patients found talking to the doctor telephonically reassuring.

Conclusions: The COVID-19 pandemic has instilled fear and anxiety among the patients of gynecological cancer preventing them to report for follow-up. Alternative strategies need to explored to render effective follow-up care to oncology patients.
\end{abstract}

Keywords: COVID-19, Fear, Gynecological cancer, Follow-up, Patient perspective

\section{INTRODUCTION}

The highly infectious Coronavirus disease 2019 (COVID19), caused by the novel Severe acute respiratory syndrome coronavirus-2 (SARSCoV-2), was declared as a public health emergency of internationa concern by the World Health Organization (WHO) in February1 2020. ${ }^{1}$ The number of cases has risen exponentially worldwide, since the identification of the index case in December 2019 as of 27th June 2020, there are 5,09,523 confirmed cases of COVID-19 with 15690 deaths in India. ${ }^{2}$ People with pre-existing non-communicable diseases, such as cardiovascular disease, respiratory illness, diabetes, hypertension, history of transplant and cancer and those belonging to the older age group are more vulnerable to the virus resulting in more severe illness in this subset of population. $^{3-5}$ The novelty of the virus along with no known cure or prevention strategy yet available for COVID-19 has led to immense fear in the population.

Most countries in the world, including India have enforced strict lockdown protocols, curbed travel and implemented 
strict social distancing protocols to limit the spread of this infectious virus in the community. ${ }^{6}$ This lockdown situation has posed a great challenge for both oncologic health care providers and cancer patients alike. Cancer patients who are due for follow up visits at oncology centres are not able to attend their scheduled visits due to lack of transport. The possible concerns could be that if their cancer will relapse because of missing their hospital visits and about the fact that their prior treatment for cancers have rendered them more vulnerable to contract COVID-19. The fear also could be that on coming out of their house they will be more at risk for contracting the illness and thus endangering themselves and their families.

Gynaecological cancers are an important public health problem in India with 155,074 new cases and 93,777 deaths every year. According to GLOBOCAN estimates, there were 96,922 new cases of cervical cancer, 13,328 new cases of endometrial and 36,170 new cases of ovarian cancer in India in $2018 .{ }^{7}$ Fear and anxiety already exist in the minds of cancer patients. ${ }^{8}$ Gynaecological cancer patients have additional stress about issues of premature menopause, fertility loss, body image issues to cope up with apart from the stress that comes with routine cancer treatments. ${ }^{9,10}$ The COVID-19 pandemic has not only exacerbated the fear and anxiety in the minds of these patients and their families but has also increased their socio-economic issues and adversely affected them on the psychosocial front. ${ }^{8}$ Doctors, health-care staff and social workers are the backbone of the health care system who create a bond with the patients and help them to be able to cope with this stress through continuous counselling. ${ }^{8}$ The present situation has rendered the patients unable to communicate with them. This has led to tremendous stress and worry in the cancer patient which may adversely affect their psychological well-being.

The current management on COVID-19 worldwide has mainly focused on infection control, formulation of vaccine and improving treatment cure rate. The psychosocial aspect has yet to be thoroughly considered. The present study aims to assess the psychological impact the disease had on gynaecological cancer patients registered in a tertiary cancer center in eastern India so as to facilitate public health initiatives on allaying public's fears in general and finding safer alternatives to rendering follow-up services for cancer.

\section{METHODS}

The present study was conducted from April to June 2020 on patients attending Chittaranjan National Cancer Institute, Kolkata, India, for follow-up after treatment of gynecological malignancies. Ethical clearance was obtained from the institute's ethics board and approval was granted for use of pre-validated questionnaire (14) for the patients enrolled in the study via telephone. One hundred six patients were eligible (received complete treatment for cancer and ascertained disease free on completion of treatment with no history of any psychiatric illness in the past), among which 96 could be contacted and 80 patients consented to take the questionnaire. These patients had completed treatment for various malignancies (cervix cancer, endometrial cancer and ovarian cancer, breast cancer) at a tertiary cancer center in eastern India. The prevalidated Fear of COVID-19 Scale (14) (FCV-19S) to assess the psychological impact of Covid-19 among the gynaecologic cancer patients attending or due for followup at the hospital was used. The questionnaire was filled through telephonic interview which was administered in the local regional language for the convenience of the patient. Statistical analysis of their response was done by descriptive statistics using Statistical package for social sciences (SPSS) version 20.

\section{Inclusion criteria}

The inclusion criteria for the study was as follows: women who have been treated for gynecologic malignancy at Chittaranjan National Cancer Institute, Kolkata and are due to attend follow up and age $>18$ years.

\section{Exclusion criteria}

The exclusion criteria for the study was as follows: patients undergoing treatment currently and patient's refusal to respond to the questionnaire.

\section{RESULTS}

The median age group of the patients was 50 years. Among the 80 patients, 22.5 percent of them were illiterate, while 35 percent of the patients were literate but uneducated.

Table 1: Level of education versus fear of contracting COVID-19 infection.

\begin{tabular}{|c|c|c|c|}
\hline \multicolumn{4}{|c|}{$\begin{array}{l}\text { Education * Fear of contracting Covid-19 } \\
\text { crosstabulation }\end{array}$} \\
\hline \multirow{2}{*}{ Education } & \multicolumn{2}{|c|}{$\begin{array}{l}\text { Fear of contracting } \\
\text { COVID-19 }\end{array}$} & \multirow{2}{*}{ Tota } \\
\hline & Yes & No & \\
\hline Illiterate & 18 & 0 & 18 \\
\hline Literate & 20 & 8 & 28 \\
\hline $\begin{array}{l}\text { School drop } \\
\text { out }\end{array}$ & 5 & 2 & 7 \\
\hline High School & 4 & 2 & 6 \\
\hline Matriculation & 5 & 3 & 8 \\
\hline Graduate & 10 & 3 & 13 \\
\hline Total & 62 & 18 & 80 \\
\hline
\end{tabular}

Majority of the patients were living with their spouses with or without their children and 11 percent were living alone. Most of the patients were treated cases of cancer cervix uteri $(n=40)$, followed by breast (20), ovary (15) and endometrium (5). All patients were aware of COVID-19 and were updated regularly. The most common source of update were television and newspapers and most patients 
who were afraid of coronavirus updated themselves at least twice a day. (Figure 1)

Approximately 78 percent of the patients were afraid of contracting COVID-19 on coming out of their house but that did not deter them from being keen on attending follow up at their hospital.(Figure 2) The higher number of poorly educated patients had fear of the corona virus infection. (Table1) In most of the patients who were afraid of contracting COVID-19, the fear stemmed from the fact that they had prior history of cancer treatment (Figure 2) and they were scared that their cancer survivor status might put them at increased risk for infection with Severe acute respiratory syndrome coronavirus-2 (SARS-CoV2). Higher number of poorly educated patients had fear of the corona virus infection due to ongoing lockdown situation (67.5 percent of the patients) (Table 2).

In questions relating to severity of symptoms the level of fear, 51 percent patients were 'very fearful' of the corona infection (table 2) and the most common cause of fear was of 'losing life due to corona virus' which was scored 4 on a scale of 5 (table 3). The telephonic conversation by a doctor was reassuring for 86 percent of the patients. (Table 4)

Table 2: Frequency of cause of most worry among patients.

\begin{tabular}{|lllll|}
\hline Cause of most worry & Frequency & $\%$ & Valid \% & Cumulative $\%$ \\
\hline $\begin{array}{l}\text { Cancer progressing/ recurring due to not going } \\
\text { to health care facility/missing follow up }\end{array}$ & 54 & 67.5 & 67.5 & 67.5 \\
\hline Getting COVID-19 on coming out of their house & 26 & 32.5 & 32.5 & 100 \\
\hline Total & 80 & 100 & 100 & \\
\hline
\end{tabular}

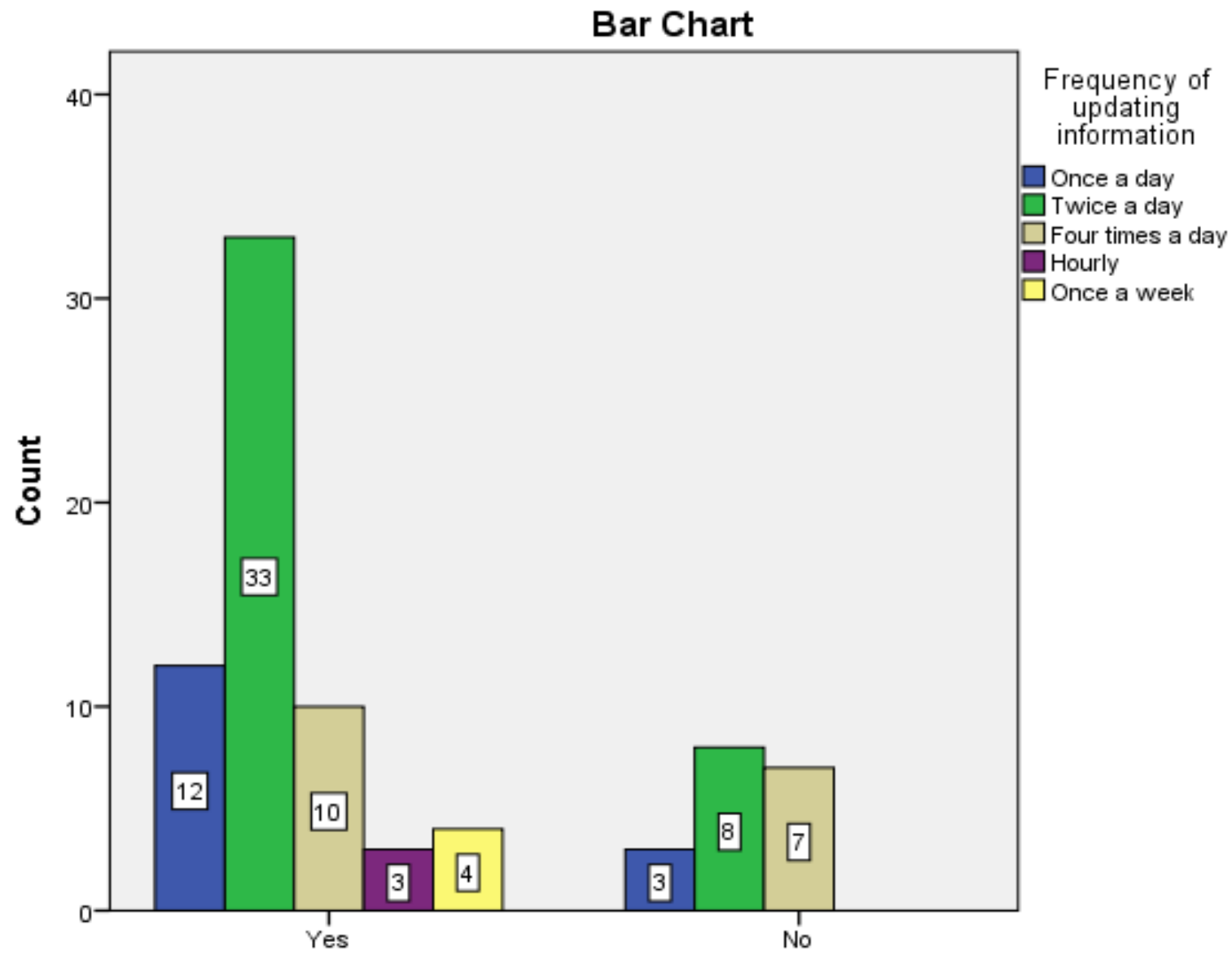

Fear of contracting Covid-19

Figure 1: Correlation of frequency of updating information with fear of corona. 
Table 3: Frequency of level of fear of contracting coronavirus infection.

How afraid are you of contracting coronavirus infection

\begin{tabular}{|lllll|}
\hline Likert scale & Frequency & Percent & $\begin{array}{l}\text { Valid } \\
\text { percent }\end{array}$ & $\begin{array}{l}\text { Cumulative } \\
\text { percent }\end{array}$ \\
\hline Not at all & 5 & 6.3 & 6.3 & 6.3 \\
\hline Some fear & 30 & 37.5 & 37.5 & 43.8 \\
\hline Quite fearful & 4 & 5.0 & 5.0 & 48.8 \\
\hline Very fearful & 41 & 51.2 & 51.2 & 100.0 \\
\hline Total & 80 & 100.0 & 100.0 & \\
\hline
\end{tabular}

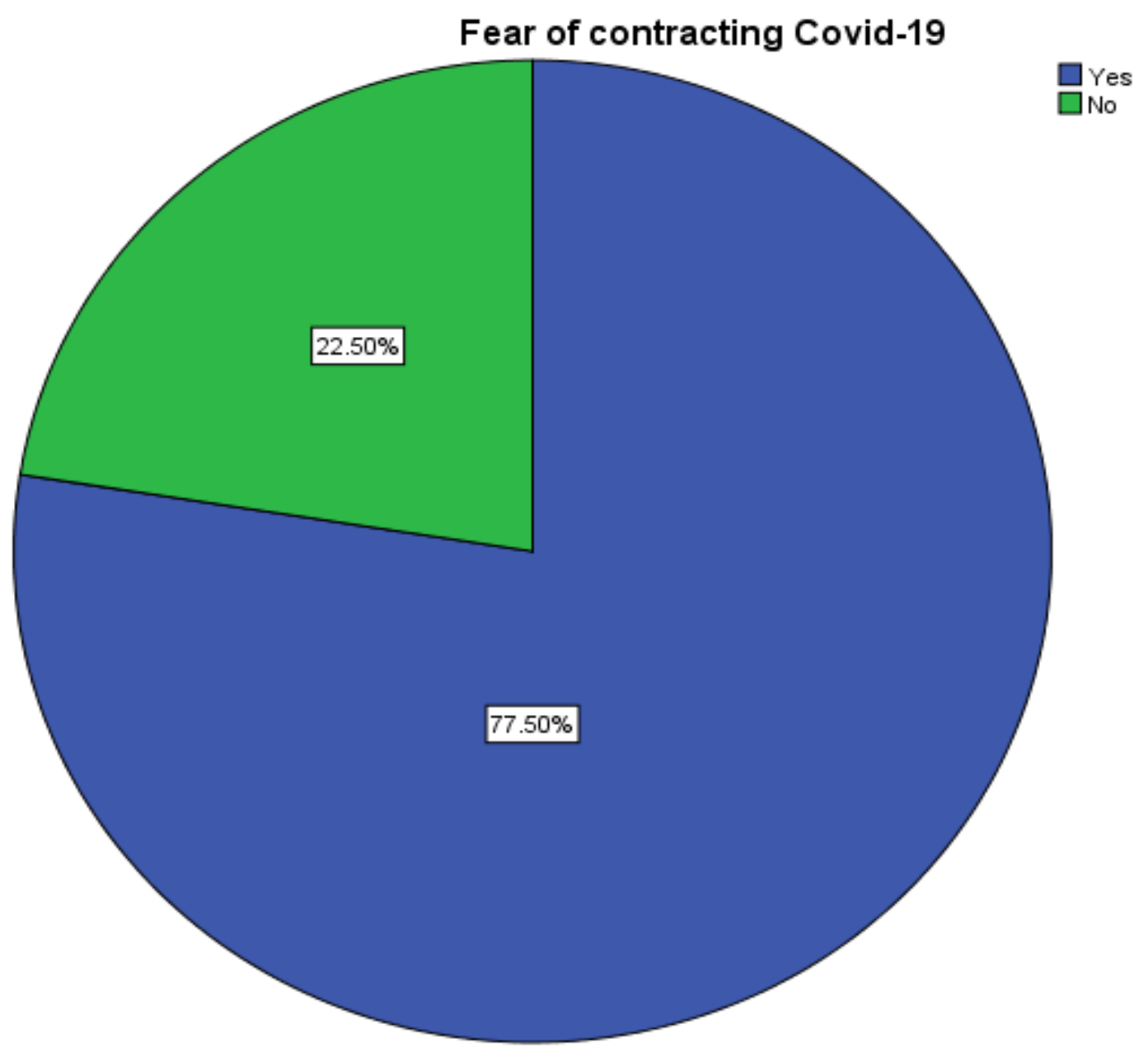

Figure 2: Frequency of Fear of contracting COVID 19 infection among patients due for cancer follow-up.

Table 4: Severity of fear of losing life due to corona virus infection.

I am afraid of losing my life because of coronavirus

\begin{tabular}{|lllll|}
\hline Scale of 5 & Frequency & Percent & $\begin{array}{l}\text { Valid } \\
\text { percent }\end{array}$ & $\begin{array}{l}\text { Cumulative } \\
\text { percent }\end{array}$ \\
\hline $\mathbf{1}$ & 16 & 20.0 & 20.0 & 20.0 \\
\hline $\mathbf{2}$ & 31 & 38.8 & 38.8 & 58.8 \\
\hline $\mathbf{4}$ & 33 & 41.3 & 41.3 & 100.0 \\
\hline Total & 80 & 100.0 & 100.0 & \\
\hline
\end{tabular}


Table 5: Response to the telephonic conversation.

\begin{tabular}{|lllll|}
\hline How do you feel after this call? & Frequency & Percent & $\begin{array}{l}\text { Valid } \\
\text { percent }\end{array}$ & $\begin{array}{l}\text { Cumulative } \\
\text { percent }\end{array}$ \\
\hline Reassured & 69 & 86.3 & 86.3 & 86.3 \\
\hline More stressed & 11 & 13.8 & 13.8 & 100.0 \\
\hline Total & 80 & 100.0 & 100.0 & \\
\hline
\end{tabular}

\section{DISCUSSION}

The public health set-ups in India are accessed majorly by the patients of low-socioeconomic strata in India, where the educational level is usually not good, the same was evident in our study where majority of the patients were either illiterate or barely could write their name. ${ }^{11}$ The result was consistent with that reported by Mertens et al showing that fear of the disease is higher among the poorly educated. ${ }^{12}$ The diagnosis and treatment of cancer can have a devastating impact on the psychological well-being of patients. ${ }^{10}$ Reports of the COVID-19 virus infection having a worse prognosis among immunologically compromised patient was a cause of concern for the cohort of patients in the current study, who were patients on follow-up after cancer treatment. The media has a role to play in generating the fear and anxiety associated with the pandemic as was also observed in the current study (Figure 2). ${ }^{12}$ The greatest cause of concern for a cancer patient is the fear of recurrence/progression which was corroborated among the patients in the study. Since the pandemic is reaching its peak in India and the number of cases is escalating by the day, measures to allay fear and anxiety associated with the pandemic is the need of the hour to decrease the number of 'worried well' patient. ${ }^{13}$ Telephonic or telemedicine-based approach to following up patients treated with cancer can be a useful alternative in the times of such a contagious pandemic. Simple measures like a telephonic counselling maybe very useful in allaying unnecessary fears among patients in particular and healthcare facilities could play a vital role in ensuring the same.

\section{CONCLUSION}

The COVID-19 pandemic has instilled fear and anxiety among the patients of gynaecological cancer and alternatives which alleviate the need to visit to the healthcare facility need to be explored to ensure timely, effective and efficient care is being provided to such patients.

Funding: No funding sources Conflict of interest: None declared

Ethical approval: The study was approved by the Institutional Ethics Committee

\section{REFERENCES}

1. The coronavirus status update. https://www.worldometers.info/coronavirus/. Accessed on 15 April, 2020.

2. Bansal N, Ghafur A. COVID-19 in oncology settings. Cancer Res Stat Treat. 2020;3:13-4.

3. Yu J, Ouyang W, Chua MLK, Xie C. SARS-CoV-2 transmission in patients with cancer at a tertiary care hospital in Wuhan, China. JAMA Oncol. 2020.

4. Liang W, Guan W, Chen R, Wang W, Li J, Xu K, et al. Cancer patients in SARS-CoV-2 infection: a nationwide analysis in China. Lancet Oncol. 2020;21:335-7.

5. World Health Organization advice for the public; 2020. World Health Organization. 2020. https://www.who.int.https://www.who.int/whodocuments-detail/covid-19-and-ncds and https://www.who.int/emergencies/diseases/novelcoronavirus-2019/advice-for-public/when-and-howto-use-masks. Accessed on 1 April, 2020.

6. Bray F, Ferlay J, Soerjomataram I, Siegel RL, Torre LA, Jemal A. Global cancer statistics 2018: GLOBOCAN estimates of incidence and mortality worldwide for 36 cancers in 185 countries. CA Cancer J Clin. 2018;68:394-424.

7. Dalal NV. Social issues faced by cancer patients during the coronavirus (COVID-19) pandemic. Cancer Res Stat Treat. 2020;3:141-4.

8. Holland JC. History of psycho-oncology: Overcoming attitudinal and conceptual barriers. Psychosom Med. 2002;64:206-21.

9. Mendosa Rd, Appaya P. Psychiatric morbidity in outpatients of gynecological oncology clinic in a tertiary care hospital. Indian J Psychiatry. 2010;52(4):327-32.

10. Rajpal S, Kumar A, Joe W. Economic burden of cancer in India: Evidence from cross-sectional nationally representative household survey, 2014. PLoS One. 2018;13(2):e0193320.

11. Mertens G, Gerritsen L, Duijndam S, Salemink E, Engelhard IM. Fear of the coronavirus (COVID-19): Predictors in an online study conducted in March 2020. J Anxiety Disord. 2020;74:102258.

12. Asmundson GJG, Taylor S. Coronaphobia: Fear and the 2019-nCoV outbreak. J Anxiety Disord. 2020;70:102196.

13. Beaver K, Williamson S, Chalmers K. Telephone follow-up after treatment for breast cancer: views and experiences of patients and specialist breast care nurses. J Clin Nurs. 19:2916-24. 
14. Ahorsu DK, Lin CY, Imani V, Saffari M, Griffiths MD, Pakpour AH. The Fear of COVID-19 Scale: Development and Initial Validation. Internat J Ment Health Addic. 2020;1:713-21.
Cite this article as: Ray C, Singh P, Mandal R. Is fear of COVID-19 influencing cancer patients to report for follow-up? experience from a tertiary care oncology center in eastern India. Int J Reprod Contracept Obstet Gynecol 2020;9:4659-64. 